\title{
Estimativas de parâmetros genéticos na população de milho CMS 35 no Estado de Sergipe ${ }^{(1)}$
}

\author{
Hélio Wilson Lemos de Carvalho(2), Maria de Lourdes da Silva Leal(2) e Manoel Xavier dos Santos ${ }^{(3)}$
}

\begin{abstract}
Resumo - O objetivo deste trabalho foi estimar parâmetros genéticos da população CMS 35 submetida a três ciclos de seleção entre e dentro de progênies de meios-irmãos, em diferentes municípios do Estado de Sergipe, no período de 1998 a 2000. Foram avaliadas 196 progênies de meios-irmãos em cada ciclo de seleção, em látice simples 14x14, em dois locais, realizando-se as recombinações das progênies selecionadas dentro do mesmo ano agrícola, de modo a se obter um ciclo/ano. A variabilidade genética foi reduzida do ciclo I para o ciclo II, e aumentou do ciclo II para o ciclo III. Os valores das estimativas dos parâmetros genéticos associados às médias de produtividade de espigas e ao ganho médio esperado, por ciclo de seleção, evidenciam o potencial da população CMS 35 em responder à seleção para aumento da produtividade, o que possibilitará a obtenção de uma variedade melhor adaptada para divulgação na região.
\end{abstract}

Termos para indexação: Zea mays, meios-irmãos, progênie, ganho genético, melhoramento de plantas.

\section{Genetic parameter estimatives in CMS 35 maize population at Sergipe, Brazil}

\begin{abstract}
The objective of this work was to estimate genetic parameters of CMS 35 population submitted to three selection cycles among and within half-sib progenies in Sergipe State, Brazil, in the 1998/2000 period. In each cycle, 196 half-sib progenies were evaluated in a 14x14 simple lattice in two local sites. The recombinations of the selected progenies were made within the same agricultural year, so that one cycle/year/was obtained. Genetic variability was reduced from the cycle I to the cycle II, and it was increased from cycle II to cycle III. The estimated parameters values associated with mean values for production and with the estimated gain for the selection show the genetic potential of CMS 35 population for increasing production and for good adaptability in the Brazilian Northeast region.
\end{abstract}

Index terms: Zea mays, half-sib, progeny, genetic gain, plant improvement.

\section{Introdução}

Cerca de três milhões de hectares do Nordeste brasileiro são destinados à cultura do milho, onde se tem constatado produtividade média de $849 \mathrm{~kg} / \mathrm{ha}$ (Anuário..., 1995). Essa área produtora encontra-se distribuída nas zonas dos Tabuleiros Costeiros, Agreste e Sertão, onde o milho é submetido a diferentes condições ambientais, tornando necessário o

\footnotetext{
(1) Aceito para publicação em 3 de junho de 2002.

(2) Embrapa-Centro de Pesquisa Agropecuária dos Tabuleiros Costeiros, Caixa Postal 44, CEP 49001-970 Aracaju, SE. E-mail: helio@cpatc.embrapa.br, lurdinha@cpatc.embrapa.br

(3) Embrapa-Centro Nacional de Pesquisa de Milho e Sorgo, Caixa Postal 152, CEP 35701-970 Sete Lagoas, MG E-mail: xavier@cnpms.embrapa.br
}

desenvolvimento de um programa intensivo de avaliação de cultivares visando fornecer alternativas aos produtores (Silva et al., 1993).

No Sertão, concentra-se a maior área plantada com o milho no Nordeste brasileiro, e é nela que o milho tem grande importância social e econômica, apesar da ocorrência de frustrações de safras, em razão do regime pluviométrico inconstante. Já no Agreste, o milho tem grande importância econômica, por ser, juntamente com o feijão, a base de sustentação familiar da maioria dos agricultores, mas em razão da regularidade climática, a ocorrência de frustração de safras é menos freqüente. Nos Tabuleiros Costeiros, a precocidade da cultivar assume importância significativa, por favorecer a colheita de duas safras dentro do mesmo ano agrícola, especialmente na faixa compreendida entre os Estados da Bahia e Alagoas. 
Nessa faixa, em que ocorre um período chuvoso constante entre os meses de março e setembro, pode-se iniciar um plantio de milho visando à produção de grãos ou de milho verde até junho, e um segundo plantio, com cultivares precoces, a exemplo da CMS 35, na segunda quinzena de junho, visando à produção de grãos (Carvalho et al., 1999).

A utilização de cultivares precoces tem sido destacada no Nordeste brasileiro (Carvalho et al., 1999, 2000b, 2001), evidenciando-se sua importância nas áreas onde são constantes as frustrações de safras, provocadas basicamente por irregularidade pluviométrica. A população de milho CMS 35, de porte baixo e ciclo superprecoce, após demonstrar bom desempenho produtivo em diversos ensaios realizados em vários anos e locais do Nordeste brasileiro, mostrou também boa estabilidade de produção nesses ambientes (Carvalho et al., 1992, 2000c, 2001).

A população de milho CMS 35 foi escolhida para ser incorporada ao programa de melhoramento intrapopulacional em desenvolvimento no Nordeste brasileiro, visando dotar os pequenos e médios produtores rurais de uma cultivar adaptada às condições do solo e clima dessa região. Sabe-se que o uso de cultivares melhoradas pode aumentar substancialmente o rendimento do milho, além de as sementes dessas cultivares se constituírem em insumos baratos e acessíveis para os produtores.

No melhoramento da população CMS 35, tem sido utilizado o método de seleção entre e dentro de progênies de meios-irmãos, pela facilidade de execução e pela eficiência em auferir ganhos genéticos às populações, tendo ainda como vantagem a possibilidade de estimar a variância genética aditiva (Paterniani, 1967). Diversas populações foram melhoradas no Nordeste brasileiro, utilizando-se esse método de seleção. Inicialmente, Santos \& Naspolini Filho (1986) desenvolveram a variedade de milho Dentado Composto Nordeste, após submeter esse material a três ciclos de seleção entre e dentro de progênies de meios-irmãos. Após a realização desses ciclos de seleção, obteve-se um material adaptado às condições edafoclimáticas da região. As populações CMS 33, CMS 28, CMS 11 e CMS 52, após demonstrarem boa adaptabilidade e estabilidade de produção na região (Carvalho et al., 1999), foram submetidas a diversos ciclos de seleção entre e dentro de progênies de meios-irmãos, e obtiveram-se as variedades BR 5033-Asa Branca (Carvalho et al., 2000e), BR 5028 São Francisco (Carvalho et al., 1994, 1998b), BR 5011 Sertanejo (Carvalho et al., 1998a, 2000d) e BRS Assum Preto (Carvalho et al., 2000b), respectivamente. Em todos esses casos, os autores constataram a eficiência do método de seleção entre e dentro de progênies de meios-irmãos, no melhoramento das populações em estudo. Enfatizaram, ainda, que a magnitude da interação progênies $x$ locais evidenciou a importância de se avaliar em mais de um local, para melhorar a eficiência do processo seletivo e obter estimativas mais consistentes dos componentes da variância.

Este trabalho teve por objetivo estimar os parâmetros genéticos da população de milho CMS 35 submetida a três ciclos de seleção entre e dentro de progênies de meios-irmãos em diferentes municípios do Estado de Sergipe.

\section{Material e Métodos}

A população de milho CMS 35 (pool 18), introduzida do Centro Internacional de Melhoramento de Milho e Trigo (Cimmyt) pela Embrapa-Centro Nacional de Pesquisa de Milho e Sorgo (CNPMS) (Relatório..., 1986), tem como principais características a superprecocidade, reduzidas alturas da planta e da inserção da primeira espiga, bom empalhamento e tipo de grão semi-duro, de coloração amarelo-laranja. Uma amostra desse material foi recebida pela Embrapa-Centro de Pesquisa Agropecuária dos Tabuleiros Costeiros (CPATC), para iniciar o programa de melhoramento para a Região Nordeste do Brasil. No ano agrícola de 1997, foi cultivada, em Aracaju, SE, uma área de $1.000 \mathrm{~m}^{2}$, onde foram obtidas 196 progênies de meiosirmãos, com base em boas características de altura da planta e de espiga, resistência ao acamamento e quebramento do colmo, prolificidade, empalhamento, tipo e coloração de grãos e disposição das fileiras na espiga. Em 1998, foi realizado, nos municípios de Neópolis e Umbaúba, SE, o ciclo I de seleção entre e dentro de progênies de meiosirmãos; os ciclos II e III foram realizados no decorrer dos anos agrícolas de 1999 e 2000, respectivamente, nos municípios de Nossa Senhora das Dores e Neópolis, SE.

Em cada ciclo foram avaliadas 196 progênies em látice $14 \times 14$ e duas testemunhas (BR 106 e BR 3123). Essas testemunhas foram escolhidas, pelo fato de apresentarem bom desempenho produtivo na região (Carvalho et al, 2000c, 2001), com duas repetições. Cada parcela constou 
de uma fileira de 5,0 m de comprimento com 0,20 m entre covas. Utilizou-se o espaçamento de $0,87 \mathrm{~m}$ entre fileiras. Após a realização dos ensaios, foi praticada uma intensidade de seleção de $10 \%$ entre as progênies. As progênies selecionadas foram recombinadas em lotes isolados por despendoamento, onde foram selecionadas 196 novas progênies, no mesmo ano agrícola. Todos os ensaios e campos de recombinação receberam adubação de N, P, e K de acordo com os resultados da análise do solo de cada área experimental.

Nesse trabalho foram considerados apenas os dados de peso das espigas, corrigidos para $15 \%$ de umidade. Realizou-se, inicialmente, a análise por local, segundo o esquema em látice. A seguir, procedeu-se à análise de variância conjunta, a partir das médias ajustadas de tratamentos, obedecendo ao critério de homogeneidade dos quadrados médios residuais. Os quadrados médios das análises de variância por local e conjunta foram ajustados para o nível de indivíduos e obtiveram-se todas as variâncias nesse nível, e expressas em (g/planta) ${ }^{2}$, conforme Vencovsky (1978).

Embora as análises tenham sido feitas em látice, as estimativas dos componentes da variância foram baseadas nas esperanças dos quadrados médios de blocos casualizados, usando-se os quadrados médios de tratamentos ajustados e o erro efetivo do látice, conforme método descrito por Vianna \& Silva (1978). Estimaram-se os coeficientes de herdabilidade no sentido restrito de médias de progênies $\left(h^{2} \mathrm{~m}\right)$ e de plantas $\left(\mathrm{h}^{2}\right)$, pelas expressões $\sigma_{\mathrm{p}}^{2} / \sigma_{\mathrm{F}}^{2}$ e $\sigma^{2}{ }_{\mathrm{A}} / \sigma^{2} \mathrm{~F}$, respectivamente, conforme apresentado por Santos \& Naspolini Filho (1986). O índice de variação b foi estimado pelo quociente $\mathrm{CV}_{\mathrm{g}} / \mathrm{CV}_{\mathrm{e}}$.

Foram estimados os ganhos da seleção, de acordo com Vencovsky (1978), e apresentado por Santos \& Naspolini Filho (1986):

$\mathrm{Gs}=\left(\mathrm{K}_{1}(1 / 4) \sigma_{\mathrm{A}}^{2} / \sigma_{\mathrm{F}}\right)+\left(\mathrm{K}_{2}\left(3 / 8 \sigma_{\mathrm{A}}^{2} / \sigma_{\mathrm{d}}\right)\right.$,

sendo: Gs: progresso genético esperado com a seleção entre e dentro de progênies de meios-irmãos; $\mathrm{K}_{1}$ : diferencial de seleção estandardizado, correspondente a uma intensidade de seleção de $10 \%\left(K_{1}=1,755\right) ; K_{2}$ : diferencial de seleção estandardizado, correspondente a uma intensidade de seleção de $10 \%\left(\mathrm{~K}_{2}=1,755\right)$; $\sigma_{\mathrm{F}}$ : desvio-padrão fenotípico entre médias de progênies; $\sigma_{\mathrm{d}}$ : desvio-padrão fenotípico dentro de progênies de meios-irmãos.

Para os cálculos dos ganhos considerou-se $\sigma_{\mathrm{d}}^{2}=10 \sigma_{\mathrm{e}}^{2}$ (Gardner, 1961).

\section{Resultados e Discussão}

A análise de variância conjunta de progênies para cada ciclo de seleção revelou diferenças significativas a $1 \%$ de probabilidade (teste F), o que expressa a presença de variabilidade genética entre elas quanto ao peso das espigas (Tabela 1). Obteve-se também evidência de interação significativa, em cada ciclo de seleção, o que expressa comportamento inconsistente das progênies nos ambientes considerados. A ocorrência de interação significativa vem sendo observada em trabalhos similares de melhoramento realizados no Nordeste brasileiro (Carvalho et al., 2000b, 2000d, 2000e). Os coeficientes de variação experimental foram baixos, e isto evidencia boa precisão dos ensaios (Scapim et al., 1995).

As progênies avaliadas produziram, em média, $4.896 \mathrm{~kg} / \mathrm{ha}$ de espigas, e as selecionadas produziram $5.977 \mathrm{~kg} / \mathrm{ha}$ de espigas, o que mostra o bom potencial para a produtividade e a boa adaptação da população CMS 35 na região (Tabela 2). Apesar de se tratar de material superprecoce, as progênies selecionadas apresentaram produtividades semelhantes às do híbrido triplo BR 3123 (testemunha); essas produtividades são relativas, isto é, de $-7,0 \%$ no ciclo I, $-6,4 \%$ no ciclo II, e $+4,1 \%$ no ciclo III. As progênies avaliadas produziram $-20,9 \%$, no ciclo I, $-13,8 \%$ no ciclo II, e $-9,6 \%$ no ciclo III, em relação à testemunha BR 106 (variedade). Nesses respectivos ciclos, as progênies selecionadas produziram $-2,7 \%$, $+2,5 \%$ e $+13,4 \%$ em relação à variedade BR 106 . Notase, pelas amplitudes das produtividades, que progênies selecionadas cada vez mais produtivas foram obtidas com o desenvolver dos ciclos de seleção.

As estimativas dos parâmetros genéticos, em todos os ciclos de seleção, são apresentadas na Tabela 3 , onde se constata uma queda da variabilidade genética do ciclo I para o ciclo II. Fato semelhante

Tabela 1. Quadrados médios das análises de variâncias conjuntas e coeficientes de variação em três ciclos de seleção de progênies da população de milho CMS 35, cultivado em diferentes municípios de Sergipe, 1998 a 2000(1).

\begin{tabular}{lcrrr}
\hline Fonte de variação & Graus de & \multicolumn{3}{c}{ Quadrado médio } \\
\cline { 3 - 5 } & liberdade & Ciclo I & Ciclo II & Ciclo III \\
\hline Progênies & 195 & $543,8^{* *}$ & $253,5^{* *}$ & $731,6^{* *}$ \\
Progênies x locais & 195 & $298,4^{* *}$ & $158,2^{* *}$ & $414,5^{* *}$ \\
Erro médio & 390 & $68,1^{* *}$ & $139,4^{* *}$ & $101,0^{* *}$ \\
\hline Médias & & 91,9 & 117,6 & 85,6 \\
CV $(\%)$ & & 9,0 & 11,1 & 11,7 \\
\hline
\end{tabular}

${ }^{(1)}$ Ciclo I: Neópolis e Umbaúba, 1998; ciclo II: N. Sra. das Dores e Neópolis, 1999; ciclo III: N. Sra. das Dores e Neópolis, 2000. ${ }^{* *}$ Significativo a $1 \%$ de probabilidade pelo teste $\mathrm{F}$. 
tem sido observado em trabalhos similares de melhoramento, utilizando esse tipo de progênie (Paterniani, 1968; Santos \& Naspolini Filho, 1986; Carvalho et al., 2000e). Conforme ressaltado por Ramalho (1977), isto ocorre em virtude da utilização máxima da variabilidade livre existente no ciclo I, e que corresponde à segregação entre blocos poligênicos. A partir do primeiro ciclo, é utilizada a variabilidade genética latente, presente dentro de blocos poligênicos, que vai sendo liberada gradativamente mediante permuta gênica. Ressaltase, também, que, em razão de as avaliações das progênies terem sido realizadas em dois locais, as magnitudes das estimativas obtidas encontram-se menos influenciadas pela interação progênies x locais.
Do ciclo II para o ciclo III, foi observado acréscimo da variabilidade. Incrementos na variabilidade genética no decorrer de ciclos de seleção têm sido descritos por Segóvia (1976) e Sawazaki (1979). Para o primeiro autor, o aumento da variabilidade observado a partir do ciclo IV de seleção com a variedade Centralmex pode ter ocorrido principalmente em razão do maior número de progênies selecionadas em cada ciclo, e à modalidade de seleção entre e dentro de progênies de meios-irmãos, que foi de um ciclo a cada dois anos. Para Sawazaki (1979), os acréscimos registrados nos ciclos XI, XII e XIII, com progênies da variedade IAC-Maya, deveu-se à introdução de algumas linhagens. No entanto, supõe-se que o acréscimo verificado no ciclo VII com a IAC-Maya

Tabela 2. Produtividade média das progênies de milho avaliadas e selecionadas nos ciclos original I, II e III de seleção, e das testemunhas BR 106 e BR 3123, e médias ajustadas das progênies avaliadas em relação à variedade BR 106, em diferentes municípios de Sergipe, 1998 a 2000.

\begin{tabular}{|c|c|c|c|c|c|}
\hline \multirow[t]{2}{*}{$\mathrm{Ciclo}^{(1)}$} & \multirow[t]{2}{*}{ Material } & \multirow{2}{*}{$\begin{array}{c}\text { Produtividade } \\
\text { média } \\
(\mathrm{kg} / \mathrm{ha})\end{array}$} & \multirow{2}{*}{$\begin{array}{l}\text { Médias } \\
\text { ajustadas } \\
\text { (kg/ha) }\end{array}$} & \multicolumn{2}{|c|}{ Porcentagem em relação às testemunhas } \\
\hline & & & & BR 106 & BR 3123 \\
\hline \multirow[t]{4}{*}{ I } & BR 106 & 5.663 & - & 100,0 & - \\
\hline & BR 3123 & 5.922 & - & - & 100,0 \\
\hline & Progênies avaliadas & 4.483 & 4.571 & 79,1 & 75,7 \\
\hline & Progênies selecionadas & 5.511 & - & 97,3 & 93,0 \\
\hline \multirow[t]{4}{*}{ II } & BR 106 & 6.650 & - & 100,0 & - \\
\hline & BR 3123 & 7.300 & - & - & 100,0 \\
\hline & Progênies avaliadas & 5.737 & 4.838 & 86,2 & 78,6 \\
\hline & Progênies selecionadas & 6.818 & - & 102,5 & 93,4 \\
\hline \multirow[t]{4}{*}{ III } & BR 106 & 4.940 & - & 100,0 & - \\
\hline & BR 3123 & 5.380 & - & - & 100,0 \\
\hline & Progênies avaliadas & 4.469 & 5.280 & 90,4 & 83,1 \\
\hline & Progênies selecionadas & 5.602 & - & 113,4 & 104,1 \\
\hline
\end{tabular}

${ }^{(1)}$ Ciclo I: Neópolis e Umbaúba, 1998; ciclo II: N. Sra. das Dores e Neópolis, 1999; ciclo III: N. Sra. das Dores e Neópolis, 2000.

Tabela 3. Estimativas obtidas, referentes às variâncias genéticas entre progênies $\left(\sigma_{\mathrm{p}}^{2}\right)$, aditiva $\left(\sigma_{\mathrm{A}}^{2}\right)$ e da interação progênies x locais $\left(\sigma^{2}\right.$ pxl $)$, coeficientes de herdabilidade no sentido restrito, com médias de progênies $\left(h^{2}{ }_{m}\right)$, e para a seleção massal $\left(\mathrm{h}^{2}\right)$, coeficiente de variação genética $\left(\mathrm{CV}_{\mathrm{g}}\right)$, relação entre o coeficiente de variação genético e o coeficiente de variação ambiental (b), e ganhos genéticos entre e dentro de progênies de meios irmãos (Gs), considerando-se o caráter peso das espigas, na população de milho CMS 35, em diferentes municípios de Sergipe, 1998 a 2000.

\begin{tabular}{|c|c|c|c|c|c|c|c|c|c|c|c|}
\hline \multirow[t]{2}{*}{$\mathrm{Ciclo}^{(1)}$} & \multirow[t]{2}{*}{$\sigma_{p}^{2}$} & \multirow{2}{*}{$\frac{\sigma_{A}^{2}}{(g / \text { planta })^{2}}$} & \multirow{2}{*}{$\sigma_{p x l}^{2}$} & \multirow[t]{2}{*}{$\mathrm{h}_{\mathrm{m}}^{2}$} & \multirow{2}{*}{$\frac{\mathrm{h}^{2}}{(\%)}$} & \multirow[t]{2}{*}{$\mathrm{CV}_{\mathrm{g}}$} & \multirow[t]{2}{*}{ b } & \multicolumn{2}{|c|}{ Gs entre } & \multicolumn{2}{|c|}{ Gs dentro } \\
\hline & & & & & & & & (g/planta) & $(\%)$ & (g/planta) & $(\%)$ \\
\hline I & 61,3 & 245,2 & 115,1 & 45,1 & 35,7 & 8,5 & 0,9 & 9,3 & 10,1 & 6,0 & 6,5 \\
\hline II & 23,8 & 95,2 & 9,4 & 37,6 & 8,6 & 4,6 & 0,4 & 5,2 & 4,9 & 1,6 & 1,5 \\
\hline III & 79,3 & 317,2 & 156,8 & 43,3 & 31,5 & 10,4 & 0,9 & 10,2 & 12,0 & 7,9 & 9,2 \\
\hline
\end{tabular}

(1)Ciclo I: Neópolis e Umbaúba, 1998; ciclo II: N. Sra. das Dores e Neópolis, 1999; ciclo III: N. Sra. das Dores e Neópolis, 2000. 
foi causado pela liberação de razoável quantidade de variabilidade potencial. No presente trabalho, supõe-se que o acréscimo ocorrido do ciclo II para o ciclo III com a população CMS 35 tenha ocorrido em consequiência da liberação de parte da variabilidade genética potencial, a exemplo do constatado por Carvalho et al. (2000a) com a população CMS 453, do ciclo I para o ciclo II.

As estimativas da variância genética entre progênies obtidas neste trabalho foram coerentes com as relatadas por Carvalho et al. (2000b, 2000e) em três ciclos iniciais de seleção, na média de dois locais; foram também concordantes com aquelas verificadas em diversas populações de milho brasileiras (Ramalho, 1977), e expressam a variabilidade genética presente na população CMS 35. Verificou-se, também, que a variação detectada na variância genética aditiva acompanhou a variação mostrada na variância genética entre progênies, concordantes com as estimativas encontradas por Carvalho et al. (2000a, 2000d). Reduções nas estimativas dessa variância do ciclo original ao ciclo I foram mostradas por Webel \& Lonquist (1967), Paterniani (1968), Carvalho et al. (1998a, 2000b, 2000d), expressando que a redução mais significativa da variabilidade genética ocorreu do ciclo original para o ciclo I. Segundo Paterniani (1968), é de interesse que a variância genética aditiva permaneça tão alta quanto possível, para permitir a obtenção de ganhos substanciais por seleção. De acordo com o referido autor, esse método de seleção reduz muito essa variância, sobretudo no primeiro ciclo de seleção; apesar disto, têm sido observados ganhos satisfatórios, a exemplo dos relatados por Sawazaki (1979), Santos \& Naspolini Filho (1986) e Carvalho et al. (2000a).

Em todos os ciclos de seleção, os valores dos coeficientes de herdabilidade no sentido restrito com médias de progênies $\left(\mathrm{h}_{\mathrm{m}}^{2}\right)$ superaram os que foram obtidos com a seleção massal, o que expressa que a seleção com progênies de meios-irmãos deve ser mais eficiente que a seleção massal; esta evidência está de acordo com Pacheco (1987) e Carvalho et al. (2000b, 2000d, 2000e).

Os valores dos coeficientes de variação genética refletem boa variação entre as progênies, em todos os ciclos de seleção, embora ela tenha sido relevante nos ciclos I e II. Os coeficientes b retratam situação mais favorável para a seleção nos ciclos I e III; os valores mostrados foram de magnitudes semelhantes aos relatados por Carvalho et al. (2000a, 2000b). Para Vencovsky \& Barriga (1992), quando o coeficiente $b$ atinge valor igual ou superior ao da unidade, na experimentação com progênies de meios-irmãos, tem-se situação muito favorável para a seleção.

Os ganhos estimados com a seleção entre e dentro de progênies de meios-irmãos foram de $10,1 \%$ e $6,5 \%$, totalizando $16,6 \%$, no ciclo I; $4,9 \%$ e $1,5 \%$, totalizando $6,4 \%$ no ciclo II e $12,0 \%$ e $9,2 \%$, totalizando $21,2 \%$ no ciclo III, com média de $14,7 \%$, por ciclo/ano, e da mesma magnitude que os ganhos registrados por Carvalho et al. (2000a, 2000b), também na média de dois locais. Tais estimativas expressam, mais uma vez, o potencial genético da população CMS 35 em responder à seleção, com vistas ao aumento da produtividade das espigas. Trabalhos na literatura têm relatado progressos genéticos esperados com a seleção entre e dentro de progênies de meios-irmãos e uso de sementes remanescentes, mas um ciclo foi completado em dois anos (Webel \& Lonquist, 1967; Paterniani, 1968). No presente trabalho, os resultados obtidos foram compatíveis com os mencionados pelos autores supracitados; no entanto, deve-se chamar a atenção para sua superioridade, visto que no presente caso tem-se um ciclo por ano.

Associando-se, então, a superprecocidade e o bom potencial da produtividade das progênies da população CMS 35 às magnitudes das estimativas dos parâmetros genéticos, nota-se que há grandes possibilidades de se obter respostas à seleção para aumento da produtividade de espigas, com o decorrer de novos ciclos de seleção.

\section{Conclusões}

1. O potencial de produtividade de espigas da população CMS 35 e as magnitudes das estimativas dos parâmetros genéticos possibilitam a obtenção de progressos genéticos para aumento da produtividade de espigas, com a continuidade do programa de melhoramento.

2. O ganho genético médio por ano, esperado com a seleção entre e dentro de progênies de meios-irmãos, é de 14,7\%. 


\section{Referências}

ANUÁRIO ESTATÍSTICO DO BRASIL. Rio de Janeiro: IBGE, v. 53, 1995.

CARVALHO, H. W. L. de; GUIMARÃES, P. E. de O.; LEAL, M. de L. da S.; CARVALHO, P. C. L. de. Avaliação de progênies de meios-irmãos da população de milho CMS-453 no Nordeste brasileiro. Pesquisa Agropecuária Brasileira, Brasília, v. 35, n. 8, p. 1577-1584, ago. 2000a.

CARVALHO, H. W. L. de; LEAL, M. de L. da S.; CARDOSO, M. J.; SANTOS, M. X. dos; CARVALHO, B. L. de; TABOSA, J. N.; LIRA, M. A.; ALBUQUERQUE, M. M. Adaptabilidade e estabilidade de cultivares e híbridos de milho no Nordeste brasileiro no ano agrícola de 1998. Pesquisa Agropecuária Brasileira, Brasília , v. 36, n. 4, p. 637-644, abr. 2001.

CARVAlHO, H. W. L. de; LEAL, M. de L. da S.; GUIMARÃES, P. E. de O.; SANTOS, M. X. dos; CARVALHO, P. C. L. de. Três ciclos de seleção entre e dentro de progênies de meios-irmãos na população de mi1ho CMS-52. Pesquisa Agropecuária Brasileira, Brasília, v. 35, n. 8, p. 1621-1628, ago. 2000b.

CARVALHO, H. W. L. de; LEAL, M. de L. da S.; SANTOS, M. X. dos; MONTEIRO, A. A. T.; CARDOSO, M. J.; CARVALHO, B. C. L. de. Estabilidade de cultivares de milho em três ecossistemas do Nordeste brasileiro. Pesquisa Agropecuária Brasileira, Brasília, v. 35 , n. 9 , p. $1773-1781$, set. 2000c.

CARVALHO, H. W. L. de; LEAL, M. de L. da S.; SANTOS, M. X. dos; PACHECO, C. A. P. Potencial genético da cultivar de milho BR 5011-Sertanejo nos Tabuleiros Costeiros do Nordeste brasileiro. Pesquisa Agropecuária Brasileira, Brasília, v. 35, n. 6, p. 11691176, jun. 2000d.

CARVALHO, H. W. L. de; MAGNAVACA, R.; LEAL, M. de L. da S. Estabilidade de produção de cultivares de milho no Estado de Sergipe. Pesquisa Agropecuária Brasileira, Brasília, v. 27, n. 7, p. 1073-1082, jul. 1992.

CARVALHO, H. W. L. de; PACHECO, C. A. P.; SANTOS, M. X. dos; GAMA, E. E. G.; MAGNAVACA, R. Três ciclos de seleção entre e dentro de famílias de meios-irmãos na população de milho BR 5011 no Nordeste brasileiro. Pesquisa Agropecuária Brasileira, Brasília, v. 33, n. 5, p. 713-720, maio 1998a.

CARVALHO, H. W. L. de; PACHECO, C. A. P.; SANTOS, M. X. dos; GAMA, E. E. G.; MAGNAVACA, R. Três ciclos de seleção entre e dentro de progênies de mei- os-irmãos na população de milho BR 5028-São Francisco no Nordeste brasileiro. Pesquisa Agropecuária Brasileira, Brasília, v. 29, n. 11, p. 1727-1733, nov. 1994.

CARVALHO, H. W. L. de; SANTOS, M. X. dos; LEAL, M. de L. da S.; CARVALHO, P. C. L. de. Melhoramento genético da cultivar de milho BR 5033-Asa Branca no Nordeste brasileiro. Pesquisa Agropecuária Brasileira, Brasília, v. 35, n. 7, p. 1417-1425, jul. 2000e.

CARVALHO, H. W. L. de; SANTOS, M. X. dos; LEAL, M. de L. da S.; PACHECO, C. A. P. Melhoramento genético da variedade de milho BR 5028-São Francisco no Nordeste brasileiro. Pesquisa Agropecuária Brasileira, Brasília, v. 33, n. 4, p. 441-448, abr. 1998 b.

CARVALHO, H. W. L. de; SANTOS, M. X. dos; LEAL, M. de L. da S.; PACHECO, C. A. P.; TABOSA, J. N. Adaptabilidade e estabilidade de cultivares de milho em treze ambientes nos Tabuleiros Costeiros do Nordeste brasileiro. Pesquisa Agropecuária Brasileira, Brasília, v. 34, n. 12, p. 2225-2234, dez. 1999.

GARDNER, A. R. An evaluation of effects of mass selection and seed irradiation with thermal neutrons on yield corn. Crop Science, Madison, v. 1, p. 241-245, 1961.

PACHECO, C. A. P. Avaliação de progênies de meiosirmãos da população de milho CMS-39 em diferentes condições de ambiente: $2^{\circ}$ ciclo de seleção. 1987. $100 \mathrm{f}$. Dissertação (Mestrado) - Escola Superior de Agricultura de Lavras, Lavras, 1987.

PATERNIANI, E. Avaliação de métodos de seleção entre e dentro de famílias de meios-irmãos no melhoramento de milho (Zea mays L.). 1968. 92 f. Dissertação (Mestrado) - Escola Superior de Agricultura Luiz de Queiroz, Piracicaba, 1968.

PATERNIANI, E. Selection among and within half-sibs families in a Brazilian populations of maize (Zea mays L.). Crop Science, Madison, v. 7, n. 3, p. 212-216, 1967.

RAMALHO, M. A. P. Eficiência relativa de alguns processos de seleção intrapopulacional no milho baseados em famílias não-endógamas. 1977. 122 f. Dissertação (Mestrado) - Escola Superior de Agricultura Luiz de Queiroz, Piracicaba. 1977.

RELATÓRIO TÉCNICO ANUAL DO CENTRO NACIONAL DE PESQUISA DE MILHO E SORGO. Sete Lagoas: Embrapa-CNPMS, v. 3, 1986. p. 21-132.

SANTOS, M. X. dos; NASPOLINI FILHO, W. Estimativas de parâmetros genéticos em três ciclos de seleção entre e dentro de famílias de meios-irmãos no milho (Zea 
mays L.) dentado composto Nordeste. Revista Brasileira de Genética, Ribeirão Preto, v. 9, n. 2, p. 307-319, 1986.

SAWAZAKI, E. Treze ciclos de seleção entre e dentro de famílias de meios-irmãos para a produção de grãos no milho IAC-Maya. 1979. 99 f. Dissertação (Mestrado) - Escola Superior de Agricultura Luiz de Queiroz, Piracicaba, 1979.

SCAPIM, C. A.; CARVALHO, C. G. P. de; CRUZ, C. D. Uma proposta de classificação dos coeficientes de variação para a cultura do milho. Pesquisa Agropecuária Brasileira, Brasília, v. 30, n. 5, p. 683-686, maio 1995.

SEGÓVIA R. T. Seis ciclos de seleção entre e dentro de famílias de meios-irmãos no milho (Zea mays L.) Centralmex. 1976. 98 f. Tese (Doutorado) - Escola Superior de Agricultura Luiz de Queiroz, Piracicaba, 1976.

SILVA, F. B. R. de; RICHE, G. R.; TORNGAU, J. P.; SOUZA NETO, N. C. de; BRITO, L. T. de L.; CORREIA,
R. C.; CAVAlCANTI, A. C.; SILVA, F. H. B. B. da; SILVA, A. D. da; ARAÚJO FILHO, J. C. de; LEITE, A. P. Zoneamento ecológico do Nordeste: diagnóstico do quadro natural e agrossocioeconômico. Petrolina: EmbrapaCPATSA/Embrapa-CNPS, 1993. v. 1.

VENCOVSKY, R. Herança quantitativa. In: PATERNIANI, E. (Ed.). Melhoramento e produção de milho no Brasil. Piracicaba: Fundação Cargill, 1978. p. 122-201.

VENCOVSKY, R.; BARRIGA, P. Genética biométrica no fitomelhoramento. Ribeirão Preto: Sociedade Brasileira de Genética, 1992. 496 p.

VIANNA, R. T.; SILVA, J. C. Comparação de três métodos estatísticos de análise de variância em experimentos em "látice" em milho (Zea mays L.). Experientiae, Viçosa, v. 24, p. 21-41, 1978.

WEBEL, O. D.; LONQUIST, J. H. An evaluation of modified ear-to-row selection in a population of corn (Zea mays L.). Crop Science, Madison, v. 7, p. 651-655, 1967. 